\title{
After-Death Communication: A Typology of Therapeutic Benefits
}

\author{
B. M. E. McCormick, MA; and Natasha A. \\ Tassell-Matamua, $\mathrm{PhD}$ \\ Massey University
}

\begin{abstract}
After-death communication (ADC) has been part of the human experience since earliest recorded history and is known to be highly beneficial to bereaved individuals who experience it. In this study, we investigated the implications of ADC among a sample of 13 participants aged between 51 and 80 years. Using semi-structured interviews, we assessed the nature of the ADC experience, how participants felt about it, and how it impacted their bereavement. Results of a thematic analysis revealed a meta-theme of affirmation-participants were unanimous in believing ADC to be beneficial, within which we found three subthemes: comfort-ADC brings comfort to the bereaved, continuity-ADC brings a sense of personal and relational continuation, and growth-ADC brings a sense of personal development. The findings support previous research that indicates spontaneous and induced ADC has overwhelmingly beneficial aftereffects.
\end{abstract}

KEY WORDS: after-death communication, death, dying, bereavement, grief

Losing a loved one through death is among the most emotionally stressful events any individual will endure, and the ensuing sense of separation may have significant, long-term implications for those surviving (Holmes \& Rahe, 1967; Rahe \& Arthur, 1978). In some cases, these implications may last a lifetime. This negative impact may be due to the commonly held view, at least in the Western world, that death is the end: the end of the deceased person's life and the end of connection between the living and the deceased (Tassell-Matamua \& Lindsay, 2015). However, recent research suggests that living persons'

B. M. E. McCormick, MA, is a graduate student in the School of Psychology at Massey University in Palmerston North, New Zealand. Natasha A. Tassell-

Matamua, $\mathrm{PhD}$, is a senior lecturer in the School of Psychology at Massey University. Correspondence regarding this article should be sent to Dr. Tassell-Matamua at the School of Psychology, Massey University, Private Bag 11222, Palmerston North, New Zealand 4442 or e-mail: n.a.tassell-matamua@massey.ac.nz. 
experiences of posthumous communication with the deceased can be an ongoing process that extends beyond physical death.

Such communication has previously been described by a number of terms, including: hallucinations of widowhood (Rees, 1971); idiophany (Barbato, Blunden, Reid, Irwin, \& Rodriguez, 1999); ideonecrophic experience (MacDonald, 1992); perceived presence (Datson \& Marwit, 1997); extraordinary experiences of the bereaved (LaGrande, 1997; Parker, 2005); afterlife encounters (Arcangel, 2005); and, post-death contact (Kalish \& Reynolds, 1973). For the purposes of the present paper, we use the term after-death communication (ADC; Guggenheim \& Guggenheim, 1995) to refer to any "experience in which a living person has a feeling or sense of direct contact with a deceased person" (Streit-Horn, 2011, p. 1).

Accounts of ADC are common, with 35 studies conducted between 1894 and 2013 indicating an estimated $25-40 \%$ of the population report an ADC at some time in their lives (Halman, 2001; Haraldsson, 1988; Streit-Horn, 2011). No specific demographic characteristics have been reliably correlated with instances of ADC, suggesting any person of any age, culture, gender, ethnicity, education level, religious affiliation-among other characteristics-may have an experience of ADC (Streit-Horn, 2011). However, some evidence suggests that parents and significant others of those who suffered traumatic deaths, as well as professionals exposed to traumatic deaths, might report ADC more often (e.g., Guggenheim \& Guggenheim, 1995; Haraldsson, 2006; Kelly, 2002; Wiener, Aikin, Gibbons, \& Hirschfeld, 1996).

ADC can be spontaneous or induced (see Botkin, 2000; Botkin \& Hogan, 2005), can manifest in a variety of forms, and may be single- or multi-sensory. Visual ADC involves visually perceiving the deceased as alive and physically manifest. Auditory ADC occurs when the living person hears the voice of or sounds associated with the deceased. Tactile ADC involves a feeling of being touched by the deceased or a physical sensing of the person's body (e.g., feeling the weight of the deceased sitting on the bed). During an olfactory ADC, a scent associated with the person who died or a particularly beautiful smell may be perceived. Sentient ADC involves sensing the presence of the deceased in the absence of other specific sensory impressions. ADC can occur in any state of consciousness, including during a sleep state, in which a particularly vivid, lifelike dream of the deceased occurs; while falling asleep or waking up; while awake and alert or in reverie; and during meditation, coma, or near-death experience. It also can occur in any health condition, ranging from perfectly healthy to 
near death (Datson \& Marwit, 1997; Field \& Friedrichs, 2004; Guggenheim \& Guggenheim, 1995; Haraldsson, 1988; Kalish \& Reynolds, 1973; Klass, 1993; Marris, 1958; Olson, Suddeth, Peterson, \& Egelhoff, 1985; Parkes, 1970; Rees, 1971; Streit-Horn, 2011; Yamamoto, Okonogi, Iwasaki, \& Yoshimura, 1969; Zingrone \& Alvarado, 2009).

\section{The Therapeutic Nature of ADC}

Research reveals that the vast majority of those who experience ADC describe its phenomenology in complimentary and beneficial terms (Streit-Horn, 2011). Therapeutic aftereffects of experiencing ADC include reduced feelings of loss, grief, guilt, and sadness; as well as changes in values; a strengthened belief in life after death; and decreased death anxiety (LaGrand, 2005). For example, Nadine Nowatski and Ruth Kalischuk (2009) investigated the effect of ADC on 23 participants whom they interviewed about the meaning and impact of the experience. Emotions the participants expressed were largely positive and associated with love, connectedness, and comfort. Many participants felt they had received a specific and meaningful message from the deceased, which often involved reassurance the deceased was fine and that the deceased loved and (when appropriate) forgave participants. Participants also reported life changes and personal growth following their ADCs, describing themselves as more compassionate toward and connected to others.

M. Damaris Drewry (2002) used semi-structured interviews to investigate the phenomenology of 40 individual ADC accounts reported by seven participants. Results indicated participants felt blessed and privileged by the experience of ADC even when they had been initially disturbed by it. ADC enabled them to conclude unfinished business with the deceased and, in some cases, to resolve their grief. Post-ADC aftereffects included reduced existential fears, expanded existential awareness, and a belief that consciousness and love persist postdeath. These spiritual or existential consequences of ADC were also supported by the findings of Edith Steffen and Adrian Coyle's (2011) thematically analyzed interviews, which showed $100 \%$ of 12 participants understood their ADCs to be indicative of life after death and had reason to hope they would one day be reunited with their loved ones. Participants also reported a reduced fear of death and increased spiritual meaning.

The collective findings of such qualitative studies are supported by quantitative research, much of which has arisen from the foun- 
dational work of psychologist Allan Botkin (2000), who developed the technique of Induced ADC (IADC) through his extensive clinical work using eye movement desensitization and reprocessing. In a recent study employing IADC within a psychotherapeutic context, 71 participants were assessed for grief symptoms, coping behaviors, and existential beliefs, prior to a two-session treatment protocol and then again both immediately following treatment and at six-month followup. Analyses revealed significant improvements in all three areas. Participants were also significantly less angry and depressed in both post-treatment periods compared to pre-treatment (Hannah, Botkin, Marrone, \& Streit-Horn, 2013). Botkin and Moe Hannah (2013) also found their sample of 16 therapists trained in Botkin's IADC reported the technique to be "between 'much better' and 'dramatically better' than other therapies used to treat grief" (p. 223). Combined, such findings support the contention of beneficial implications following experiences of ADC.

\section{Present Study}

The beneficial impact of ADC is well established, but less so are the reasons why ADC catalyzes such positive aftereffects, although some authors have speculated (e.g., Arcangel, 2005; Botkin, 2000; Hastings et al., 2002; Kalish \& Reynolds, 1973). The purpose of this study therefore was to build on previous ADC literature and offer a foundational qualitative understanding of some of the reasons for ADCs' benefits.

\section{Participants}

We recruited participants via a snowballing technique and through our established professional networks. We extended an invitation to adults who were fluent in English and who had had the experience of contact with a deceased loved one to participate in an interview about the experience(s) and aftereffects. Once we identified participants, we verbally informed them about the study, invited them to take part, and provided them with additional information via email. Participants who wished to proceed with an interview were invited to email co-author McCormick, after which she replied by email with potential interview questions and scheduled the interviews. Interviews were conducted face-to-face when possible and by Skype when necessary. The interview technique was semi-structured, and verbal prompts were given when required to elicit more information (Break- 
well, 1995). The open-ended questions covered the participant's relationship with the deceased, the participant's state of bereavement, the type of $\mathrm{ADC}(\mathrm{s})$, the perceived significance of the $\mathrm{ADC}(\mathrm{s})$, and the impact of the ADC(s) on the participant's grief, spiritual beliefs, and attitudes toward death. Interview lengths ranged from 20 to 30 minutes.

A total of 13 participants comprised the sample. Table 1 provides an overview of participant demographics.

Across the 13 interviews, participants reported 19 individual ADC experiences because some participants experienced ADC from more than one deceased. Table 2 provides a general overview of each participant's ADC experience(s).

Table 1 Participant Demographics

\begin{tabular}{|c|c|c|c|c|c|c|c|}
\hline Participant & Gender & $\begin{array}{c}\text { Religious } \\
\text { Affiliation }\end{array}$ & Age & $\begin{array}{c}\text { Educational } \\
\text { Level }\end{array}$ & $\begin{array}{c}\text { Marital } \\
\text { Status }\end{array}$ & Residence & Ethnicity \\
\hline $1 \mathrm{NZCF}$ & $\mathrm{F}$ & $\begin{array}{l}\text { Spiritual not } \\
\text { Religious }\end{array}$ & 76 & graduate & widow & Auckland & $\begin{array}{l}\mathrm{NZ} \\
\text { Caucasian }\end{array}$ \\
\hline $3 \mathrm{SwCF}$ & $\mathrm{F}$ & Agnostic & 68 & graduate & married & $\begin{array}{l}\text { San } \\
\text { Francisco }\end{array}$ & $\begin{array}{l}\text { Swedish } \\
\text { Caucasian }\end{array}$ \\
\hline $4 \mathrm{NZCM}$ & M & Christian & 56 & college & single & Auckland & $\begin{array}{l}\mathrm{NZ} \\
\text { Caucasian }\end{array}$ \\
\hline $5 \mathrm{NZCF}$ & $\mathrm{F}$ & $\begin{array}{l}\text { Spiritual not } \\
\text { Religious }\end{array}$ & 80 & college & widow & Auckland & $\begin{array}{l}\mathrm{NZ} \\
\text { Caucasian }\end{array}$ \\
\hline $6 \mathrm{NZCF}$ & $\mathrm{F}$ & $\begin{array}{l}\text { Spiritual not } \\
\text { Religious }\end{array}$ & 59 & graduate & divorced & Wellington & $\begin{array}{l}\mathrm{NZ} \\
\text { Caucasian }\end{array}$ \\
\hline 7UKCF & $\mathrm{F}$ & Spiritual & 59 & college & married & Auckland & $\begin{array}{l}\text { English } \\
\text { Caucasian }\end{array}$ \\
\hline $8 \mathrm{NCF}$ & $\mathrm{F}$ & Christian & 63 & graduate & divorced & $\begin{array}{l}\text { San } \\
\text { Francisco }\end{array}$ & $\begin{array}{l}\text { Norwegian } \\
\text { Caucasian }\end{array}$ \\
\hline 9IndM & M & Buddhist & 73 & graduate & married & $\begin{array}{l}\text { San } \\
\text { Francisco }\end{array}$ & $\begin{array}{l}\text { Zapotec } \\
\text { Indian }\end{array}$ \\
\hline $10 \mathrm{AmCF}$ & $\mathrm{F}$ & Jewish & 59 & postgraduate & divorced & $\begin{array}{l}\text { San } \\
\text { Francisco }\end{array}$ & $\begin{array}{l}\text { American } \\
\text { Caucasian }\end{array}$ \\
\hline $11 \mathrm{AmCF}$ & $\mathrm{F}$ & Christian+ & 52 & college & married & Los Angeles & $\begin{array}{l}\text { American } \\
\text { Caucasian }\end{array}$ \\
\hline $12 \mathrm{AmCM}$ & M & Christian+ & 67 & postgraduate & married & Los Angeles & $\begin{array}{l}\text { American } \\
\text { Caucasian }\end{array}$ \\
\hline $13 \mathrm{AmCF}$ & $\mathrm{F}$ & Jewish & 51 & graduate & widow & Los Angeles & $\begin{array}{l}\text { American } \\
\text { Caucasian }\end{array}$ \\
\hline $14 \mathrm{AmCF}$ & $\mathrm{F}$ & Buddhist & 54 & college & married & Los Angeles & $\begin{array}{l}\text { American } \\
\text { Caucasian }\end{array}$ \\
\hline
\end{tabular}


Table 2 Details of Participants' ADCs

\begin{tabular}{|c|c|c|c|c|c|}
\hline Participant & ADC From & $\begin{array}{l}\text { ADC State of } \\
\text { Consciousness }\end{array}$ & ADC Type & $\begin{array}{c}\text { Time Since } \\
\text { Death of } \\
\text { Communicant }\end{array}$ & $\begin{array}{c}\text { Effect on } \\
\text { Grief }\end{array}$ \\
\hline $1 \mathrm{NZCF}$ & $\begin{array}{l}\text { husband } \\
\text { friend } \\
\text { acquaintance }\end{array}$ & $\begin{array}{l}\text { awake } \\
\text { awake } \\
\text { awake }\end{array}$ & $\begin{array}{l}\text { tactile } \\
\text { kinesthetic } \\
\text { kinesthetic }\end{array}$ & $\begin{array}{l}1 \text { week } \\
3 \text { days } \\
\text { days }\end{array}$ & $\begin{array}{l}\text { reduced } \\
\text { reduced } \\
\text { no change }\end{array}$ \\
\hline $3 \mathrm{SwCF}$ & $\begin{array}{l}\text { mother } \\
\text { husband }\end{array}$ & $\begin{array}{l}\text { awake } \\
\text { awake }\end{array}$ & $\begin{array}{l}\text { visual } \\
\text { visual }\end{array}$ & $\begin{array}{l}1 \text { month } \\
\text { days }\end{array}$ & $\begin{array}{l}\text { reduced } \\
\text { reduced }\end{array}$ \\
\hline 4NZCM & $\begin{array}{l}\text { partner } \\
\text { partner }\end{array}$ & $\begin{array}{l}\text { awake } \\
\text { awake }\end{array}$ & $\begin{array}{l}\text { tactile } \\
\text { sense of } \\
\text { presence }\end{array}$ & $\begin{array}{l}1 \text { day to } 1 \text { year } \\
1 \text { day to } 1 \text { year }\end{array}$ & $\begin{array}{l}\text { reduced } \\
\text { reduced }\end{array}$ \\
\hline $5 \mathrm{NZCF}$ & cousin & awake & kinesthetic & days & no change \\
\hline $6 \mathrm{NZCF}$ & $\begin{array}{l}\text { dog } \\
\text { father }\end{array}$ & $\begin{array}{l}\text { awake } \\
\text { awake }\end{array}$ & $\begin{array}{l}\text { visual } \\
\text { visual }\end{array}$ & $\begin{array}{l}\text { days } \\
\text { unknown }\end{array}$ & $\begin{array}{l}\text { ambiguous } \\
\text { reduced }\end{array}$ \\
\hline 7UKCF & $\begin{array}{l}\text { son } \\
\text { son }\end{array}$ & $\begin{array}{l}\text { awake } \\
\text { awake }\end{array}$ & $\begin{array}{l}\text { auditory } \\
\text { sense of } \\
\text { presence }\end{array}$ & $\begin{array}{l}18 \text { months } \\
18 \text { months }\end{array}$ & $\begin{array}{l}\text { reduced } \\
\text { reduced }\end{array}$ \\
\hline & mother & awake & kinesthetic & 1 year & reduced \\
\hline $8 \mathrm{AmCF}$ & mother & awake & $\begin{array}{l}\text { sense of } \\
\text { presence }\end{array}$ & $\begin{array}{l}\text { days to present } \\
\text { (13 years total) }\end{array}$ & reduced \\
\hline 9IndM & friend & awake & $\begin{array}{l}\text { sense of } \\
\text { presence }\end{array}$ & days & ambiguous \\
\hline & friend & awake & auditory & days & ambiguous \\
\hline $10 \mathrm{AmCF}$ & mother & asleep & dream & days & reduced \\
\hline $11 \mathrm{AmCF}$ & father & awake & auditory & weeks & reduced \\
\hline $12 \mathrm{AmCM}$ & father-in-law & awake & kinesthetic & days & reduced \\
\hline $13 \mathrm{AmCF}$ & $\begin{array}{l}\text { dog } \\
\text { father-in-law }\end{array}$ & $\begin{array}{l}\text { awake } \\
\text { asleep }\end{array}$ & $\begin{array}{l}\text { kinesthetic } \\
\text { dream }\end{array}$ & $\begin{array}{l}\text { weeks } \\
\text { days }\end{array}$ & $\begin{array}{l}\text { reduced } \\
\text { reduced }\end{array}$ \\
\hline $14 \mathrm{AmCF}$ & husband & awake & olfactory & $\begin{array}{l}8 \text { months- } \\
\text { lasted } 4 \text { days }\end{array}$ & increased \\
\hline
\end{tabular}

\section{Procedure}

Once we completed the interviews, we transcribed them and then thematically analyzed them using the protocol outlined by Braun and Clarke (2006), which is "a method of identifying, analyzing and reporting patterns (themes) within data" (p. 79). This process involved an initial coding: identifying broad topics within the explicit content 
of the data. We then used the various codes to construct themes. Upon reviewing the themes, we identified a meta-theme and then subsequently refined it into three sub-themes. Throughout this process, each of us first independently identified codes and themes, and then we consulted together to seek consensus, which we reached to a very high degree.

\section{Results}

The overriding message we detected in the reported experience of ADC was one of affirmation. Participants overwhelmingly conveyed their experiences in positive terms, indicating they were beneficial for a number of reasons. Importantly, responses indicated ADC was a useful and effective tool in grief resolution. The themes apparent in the data set were subsumed under this overriding meta-theme of affirmation. We then examined the reasons we had identified in the data as to why ADC was beneficial and categorized them into the subthemes of comfort, continuation, and growth. Each of these themes will be described below, with relevant quotes from participants to exemplify each theme.

Comfort. Participants expressed the sub-theme of comfort largely through positive expressions about the enjoyable nature of the ADC and the implications this quality of experience had for their grieving processes. All 13 participants indicated their ADC was enjoyable, using affirmative and emotive statements such as:

I loved it. I thought it was amazing. [6NZCF]

I felt good, happy. I felt relieved. [7UKCF]

The overall feeling was one of warmth. [6NZCF]

I was grateful; thrilled . . . it was the feeling that was reassuring. [10AmCF]

Twelve participants reported experiencing some form of comfort from their ADC, and five specifically used the word "comfort" to describe the impact of the experience. Ten participants indicated a more direct implication of this comforting process was the facilitation of "closure" and "strength":

It is also comforting when they make contact because you know that even though they have moved on, they have not forgotten us. [1NZCF] 
It meant closure for me. [1NZCF]

It cheered it [bereavement] up enormously . . . It gave me the strength to go on. [4NZCM]

Of the 19 ADC experiences, four (involving four different participants) did not result in resolved grief. One participant said her grief was already resolved, two had not experienced intense grief, and one said her ADC made her feel worse. In the latter case, it did not make her grief more intense. Rather, it instead made her angry, and possibly frustrated at being prevented from "getting through" her grief in a timely manner:

I got very angry. How am I supposed to get through this if I keep getting reminded of you? [14AmCF]

Continuation. A second sub-theme we identified was that of continuation, evidenced in the ideas of a continued relationship with the deceased and a continued personal existence beyond physical death. A total of 11 participants reported a sense of a continued relationship with the deceased. Others further suggested they believed the continued relationship expressed in ADC was initiated by the deceased and that participants themselves could (and would) also engage in ADC following their own physical deaths. Statements indicative of these ideas included:

It made me feel better to know that our love had endured. [4NZCM]

I felt I was still connected with him. [9IndM]

Hearing from her made me feel like I still had like, I still had my family. [10AMCF]

He just wants to keep connected ... It wasn't really his time but he had to go and I just think that he is trying to keep connected with us. [13AmCF]

I expect to be giving ADCs myself. [1NZCF]

I want ... to give a message that I am not gone I am just in a different dimension. [10AmCF]

I promised the youngest one ... that when I pass, and after I have time to rest, and gain strength, that I would reach out to him. [14AmCF]

Continuation was also expressed in the form of belief in the continued existence of the non-physical self-identity after the death of the physical body. Eleven of the 13 participants stated ADC strengthened 
their belief in such continuation, and this strengthening facilitated positive grief resolution. Statements indicative of this feature included:

$\mathrm{ADC}$ helps bereavement because it shows consciousness continues. It is proof. [1NZCF]

Signs are a help because I was very painfully bereaved by Marg's death ... and ADC helps bereavement because it shows consciousness continues. [1NZCF]

It did affect my bereavement because I knew, to me, that was a positive affirmation-confirmation, that there was a spirit. Absolutely, $100 \%$. [7UKCF]

You die; physically you just disintegrate into the ground, end of story. But I believe your soul, or your spirit or whatever, goes higher or lower or wherever. [7UKCF]

I knew there was more to life and death. I just knew there was something more. [4NZCM]

Growth. A final theme to emerge was growth, which was evident through statements related to participants' personal development as a result of the ADC. Overwhelmingly, participants suggested the experience had facilitated a positive change in the way they viewed life, which mainly related to philosophical concerns about how life should be lived or beliefs about what constitute the important things in life. Five participants specifically reported the changes as manifesting a personal growth:

It gave me the strength to go on. It increased my world . . . it made me a searcher of truth and history ... it changed my internal world. [4NZCM]

I felt it was a tune up for me, an instruction for me to be who I am supposed to be and not who I thought I should be. [4NZCM]

All of it has made me want to give back and help others. [13AmCF]

Other growth oriented expressions related to a desire to learn more, mainly about ADCs and what they might mean. Several participants extended this notion of their own growth by indicating a desire to share the information they gained about ADC with the world at large so as to promote others' growth:

It made me more excited to talk about it and look into it more, to read about it more. I am thirsty for this information. [13AmCF] 
I wanted the world to understand that there's more going on. I had spiritual discovery excitement and I wanted to share the excitement. [4NZCM]

I did [want to talk about ADC] because I thought it was important . . . I think it was important that they realize that it does exist . . . that there is something after death, and it's important people know that. Maybe it will take some of the fear away, and maybe people when they pass they can be a little more at peace. [14AmCF]

Six participants reported the growth they felt had occurred was spiritual in nature. Some statements highlighting this claim included:

It made them [spiritual beliefs] stronger. We are all connected. We are all part of each other, and the more we discover with science the more that is confirmed. [4NZCM]

It drove me to try to understand our spiritual nature, and it made it [spiritual belief] stronger and more solid. [7UKCF]

Perhaps the most prominent discourse within the main theme of growth related to a reduction or resolution of death fear and of existential concerns, with 11 of the 13 participants indicating they no longer held a fear of dying. However, one participant reported death fear but said ADC had helped reduce it:

These experiences combined with research on my own part and the expansion of my knowledge about post-death communication and what might lie beyond this life will make dying not such a terrifying prospect at some point in my life. [11AmCF]

I am not afraid although it is not an easy thing to go through, from what I have seen. It has dispelled any fear I had. [8AmCF]

It made me feel not afraid of death. [9IndM]

It gave me comfort about my own passing in the future. [12AmCM]

I am still afraid of death . . . But I think that the post-death communication I have had with my father . . . is helping me to slowly change that fear. [11AmCF]

The growth experienced through ADC also involved a healing dimension for one participant who had previously had a painful relationship with her mother:

I felt relieved as if I had got that relationship back with her that every child wants with their parent ... The ADC from my mother made me feel great. It put a positive spin on what was a very tough relationship. I speak with Mum on a regular basis now and have a great 
relationship with her, and I have told my family and they all think it's great that we have finally become friends. [7UKCF]

\section{Discussion}

The purpose of this study was to build on previous ADC literature and to offer a foundational qualitative understanding of some of the benefits of ADCs. Consonant with previous research, the overriding single theme inherent to the data was affirmation, with participants indicating the positive nature of ADCs as well as a sense that the experiences assisted with the grieving process. Of the 19 ADC relationships considered in this study, 13 eased or resolved the grief status of the participant. Assistance with grief resolution is a finding that pervades the ADC literature (e.g., Botkin \& Hannah, 2013; Drewry, 2002; Hannah et al., 2013; LaGrand, 2005; Nowatski \& Kalischuk, 2009; Steffen \& Coyle, 2011). The reasons for this resolution were implicitly portrayed by participants in the present study, and we categorized these reasons into the sub-themes of comfort, growth, and continuation. Each of these sub-themes is described below in relation to previous research and the possible role of the sub-theme in grief resolution.

\section{Comfort}

The majority of participants found comfort from their ADCs, which was expressed through descriptions of the actual ADC experiences themselves as well as the implications of the experiences. For example, the vast majority of participants reported their ADCs were enjoyable and used expressions such as happy, joyous, love, and comfort to describe their experiences. This positive and comforting nature is supported by findings of other studies that show the experience of ADC reported in positive ways. According to Jenny Streit-Horn (2011), who conducted a systematic review of ADC research, experiencers felt their ADCs were "positive, healing, life-changing, comforting, consoling, transformative, life-saving, joyful, uplifting and/or pleasant" (p. 60; see also Guggenheim \& Guggenheim, 1995; LaGrand, 1997, 1999; Long, 1999). Among the studies she reviewed was that of Diana Arcangel (2005) who found that of 596 respondents claiming to have ADC, 583 (98\%) said the experience brought them comfort. Such findings also align with those of the near-death experience (NDE) and end-of-life 
experience (ELE) literature, which indicate both the contents and aftereffects of NDEs and ELEs are usually described in similarly positive terms (e.g., Greyson, 2003; Noyes, Fenwick, Holden, \& Christian, 2009; Schwaninger, Eisenberg, Schectman, \& Weiss, 2002; TassellMatamua \& Steadman, 2015; Zingrone \& Alvarado, 2009).

The comfort evoked by ADC inevitably plays a role in grief resolution. Although it is difficult to state conclusively why this effect might occur, Callum Cooper (2013) suggested comfort relates to a sense of hope that the loved one is still present, albeit non-physically. Conceptualizations in many Western societies suggest death as an annihilation of the self, beyond which nothing of the person continues to persist (Carpentier \& Van Brussel, 2012). Proponents of terror management theory (Solomon, Greenberg, \& Pyszczynski, 1991) have suggested that mortality awareness, which may be exacerbated by the death of a close other, facilitates high levels of existential anxiety. Yet, irrespective of the often unverifiable nature of ADCs, their occurrence to a bereaved individual contravenes this perception of death as annihilation. This experience likely serves to alleviate the anxiety typically associated with death and mortality awareness, by reassuring the bereaved individual the deceased "lives on," as well as by providing reassurance to the bereaved about one's own eventual death. ADCs may suggest if the loved one has survived physical death, it is reasonable to assume that at physical death the bereaved might also survive and be reunited with loved ones. Combined, this loss of anxiety and sense of persistence after death are possible underlying psychological mechanisms creating the sense of comfort typically reported by those who experience ADC. This sense of comfort, in turn, assists the grieving process.

Although findings generally advocate comfort as an important aspect of grief resolution, two participants in the present study reported no relief from experiencing ADC. Of the two, one stated she never really liked the acquaintance from whom she received the communications. This same lack of relationship and emotion was found by Richard Kelly (2002) who showed ADC can be experienced in the absence of bereavement or of a significant personal relationship with the deceased. The other participant reporting no grief relief suggested it was because she was over the worst of her grief by the time she experienced the ADC. Although ADC is strongly associated with bereavement and is a normal part of the grieving process (Arcangel, 2005; Drewry, 2003; Guggenheim \& Guggenheim, 1995; LaGrand, 1999, 2005; Worden, 2002), this finding suggests it can occur in the total 
absence of bereavement and even once the grief has resolved-a finding consonant with Streit-Horn's (2011) results. A further ADC experience reported in the present study was not considered comforting in any way due to the renewed feelings of loss the experience evoked. This particular experience aligns with other findings (e.g., Devers, 1997; Marris, 1974; Nowatski \& Kalischuk, 2009; Shuchter \& Zisook, 1988; Steit-Horn, 2011; Vickio, 1999) that indicate some experiencers are upset by their ADCs, not because the experience wasn't positive, but because it ended and meant losing the loved one all over again.

\section{Continuity}

In contrast to the finality often associated with death, a sense of continuation, found in the ADC relationship between the deceased and the participant, was a strong sub-theme. Eleven participants reported a sense of continued relationship with the deceased and believed this continuation indicated death is not final. Much of the dialogue relating to continuity reflected a belief that the deceased had transformed and that their consciousness or soul continued on another plane of existence. This outcome of ADC is consistent with what Cooper (2013) found: "The deceased can . . . be understood by the bereaved, not as ceasing to be, but having entered a transformation into what we may call spiritual form" (p. 25). It also supports Arthur Hastings et al.'s (2002) findings that spirituality is a consistent theme in the qualitative ADC literature and that experiencers are usually convinced they have had communication from the surviving consciousness, soul, or spirit of their deceased loved ones. Authors in the NDE and ELE literature also have spoken to the notion of continuation of the consciousness, soul, or essence of the dead through accounts of seeing deceased others during such experiences (e.g., Alvarado, 2014; Lawrence \& Repede, 2013), including experiences in which someone not known to have died is encountered during an NDE (Greyson, 2010; van Lommel, 2004). NDE literature also overwhelmingly indicates those who report an NDE tend to report a belief in the continuation of a soul or consciousness after physical death (e.g., Tassell-Matamua \& Murray, 2014), suggesting possible similarities between ADC, ELE, and NDEs that facilitate this similar belief across the experiences despite their differing phenomenology.

Perhaps this belief in continuity of existence is aligned with the concept of continuing bonds, defined as an ongoing, internal relationship between a bereaved person and the dead loved one (Stroebe, Schut, \& 
Stroebe, 2005). A perception of continuing bonds in the bereaved is regarded as a key factor in reducing the pain of grief (Asai et al., 2010; Barbato et al., 1999; Klugman, 2006; Nowatzki \& Kalischuk, 2009). This pain reduction is due to the sense of connection found when bonds are maintained via "loving in separation" rather than "loving in presence" (Attig, 2004, p. 213; Nowatski \& Kalischuk, 2009). The sub-theme of continuity expressed by the majority of participants in the present study may be explained by the theory of continuing bonds whereby ADC serves to reinforce a continuing relationship (Klugman, 2006).

Only one participant stated no belief in continued existence of the deceased as some sort of entity (i.e., soul, consciousness, essence). She did however still experience ADC as offering continuity, although her construct was a belief that the deceased did not continue to exist independently but instead lived on inside of her. She also reported experiencing ADC in a beneficial way. This specific finding is supported by the work of Julie Parker (2005) who stated: "Even for those who do not believe in an afterlife, they sometimes hold beliefs that give them a sense of continuity" (p. 262). Eleven participants reported ADC from their loved ones led them to conclude that they too would continue to exist post-death, and three stated a desire to be providing ADC themselves one day. Interestingly, one participant stated in her interview in December 2013: I expect to be giving ADCs myself. Shortly after that she died suddenly, and after her funeral in January 2014, another participant who was the cousin of the recently deceased experienced what she believed was ADC from the deceased former participant.

A sense of continuation may also assist with grief reduction by serving a further function. Specifically, one participant in the present study reported ADC mended a formerly difficult relationship with the deceased. This result has also been reported in previous literature (e.g., Botkin, 2000; Streit-Horn, 2011); for example, Edie Devers (1994) contended that "many times the reconnection provided the opportunity to resolve old issues between the deceased and the living person" (p. 66). The grief resolution felt by this participant in the present study may also be explained by the notion of continuing bonds, whereby the unresolved difficulties of the relationship, which may have constituted a barrier to a sense of continuing bonds, were resolved via the ADC, thus removing the barrier and enabling the participant to experience a sense of continuing bonds that resulted in her grief reduction. 


\section{Growth}

Grief is understood to have an adaptive outcome when positive changes, such as spiritual and personal growth and the reduction of existential fear, occur (Gamino, Sewell, \& Easterling, 2000; Parker 2005; Tyson-Rawson, 1996). All participants in the present study described some form of personal growth from ADC. This outcome was evidenced in statements that spoke to a sense of spiritual reassurance, benevolence, a desire to learn and share with others, a sense of expanded awareness, a sense of purpose, and a shift in values and beliefs. These types of spiritual progressions have been reported in other ADC studies. Parker (2002) noted "positive cognitive, emotional, spiritual, behavioral and/or existential changes" in participants as a result of their ADCs (p. 267). Drewry (2002) found participants felt an expanded sense of existential awareness, whereas Steffen and Coyle (2011) reported their participants felt an increased spiritual meaning to their lives. Again, such findings resonate with NDE literature, which indicates similar benevolent aftereffects for experiencers (Greyson \& Khanna, 2014; Khanna \& Greyson, 2014).

It is difficult to ascertain the mechanism responsible for such beneficial growth post-ADC. ADC deviates from conventional Western understandings of the self and one's relationship to the world. In modern Western societies, such understandings are based on a reductionist, materialist philosophy that emphasizes established scientific principles and laws, such as cause-and-effect, objectivity, materiality, positivism, and empirical verification. These perspectives form the basis for normative perceptions of reality. Any human experience contravening these understandings that cannot be objectively verified for its "reality" is often considered anomalous and subject to criticism. Because of this perspective, ADC might be expected to result in less beneficial outcomes and to serve as an inhibitor of personal growthyet the opposite appears to occur. Perhaps because ADC contravenes conventional notions of reality, time, and place, it provides the experiencer with a refreshed perspective of the world, which in turn gives meaning to the ADC and enables the growth tendencies reported in the present study to be explored. Such exploration, in turn, assists in the grief resolution process by diverting attention away from cognitions associated with loss of the bereaved and toward gains/regains of ongoing relationship and other affirming aspects.

A further aspect of growth highlighted by the majority (11 of the 13) of participants in the present study was an overwhelming loss or re- 
duction in the fear of death. Beliefs about the afterlife and a reduction in the fear of death are cited aftereffects of other ADC studies (e.g., LaGrand, 2005). They are also overwhelmingly reported by those who have experienced an NDE (e.g., Flynn, 1986; Lai et al., 2007; Noyes et al., 2009; Ring, 1984; Sabom, 1982; Sutherland, 1990; van Lommel, van Wees, Meyers, \& Elferrich, 2001), which again points to the possibility of phenomenological similarities between ADCs and NDEs that facilitate these similar outcomes. That a belief in the afterlife is beneficial to the bereaved is confirmed by Peggy Smith, Lillian Range, and Ann Ulmer (1991-1992) and by Parker (2002) who found belief in an afterlife was associated with greater recovery from bereavement regardless of the cause of death.

Why belief in an afterlife leads to greater recovery of the bereavement process is again subject to speculation. However, Parker (2002) noted that "the cognitive-affective reinforcement of life's continuity can also ease fear about the bereaved's own eventual death" (p. 277). NDE research indicates afterlife beliefs correspond with decreases in the fear of death (e.g., Flynn, 1986; Grey, 1985; Greyson \& Stevenson, 1980; Noyes et al., 2009; Ring, 1980; Sabom, 1982; Sutherland, 1990), and a reduction or loss of the fear of death in turn is related to involvement in compassionate activities, greater self-actualization, higher levels of self-esteem, a deepening of spiritual focus, and belief one is living a more meaningful life (Tassell-Matamua \& Lindsay, 2015). Given these relationships, it is possible the reduced death fear and increased afterlife beliefs felt after an ADC facilitate personal growth through greater engagement in benevolent activities, an increase in personal meaning to one's life, and positive changes to values and beliefs. These changes in turn assist the bereaved individual with the grieving process, enabling greater recovery.

\section{Limitations}

A number of limitations restrict interpretation of the findings. First, participants were a relatively homogenous group-predominantly Caucasians who clustered around the age range of 51 to 80 . It is possible that older Caucasian people hold a specific perspective on death, having possibly been exposed to death more as a consequence of their age and ethnic status. Similarly, the majority of participants reported having some form of spiritual belief. It is reasonable to assume prior spiritual belief may impact the experience of ADC. Despite the variation in self-designation of religion, all participants were from societies 
where the ethos of Christianity is dominant. It is likely religious belief impacts ADC phenomenology as well as both understandings placed on the experience and aftereffects of it. For example, depending on personal perspective and/or cultural norms, ADC could be equally labelled as "anomalous" or "transcendental," which may lead to differing interpretations of the experience. Ideally, future research should recruit ethnically and religiously diverse and age-distributed samples, allowing for a more in-depth analysis and explication of whether the same positive aftereffects of ADC occur for people of different ethnicities, ages, religions, and belief systems.

There is currently no standardized means of determining whether the experiences reported were actually ADC or some other type of experience. Even though we were interested in exploring the phenomenology of the experiences from the participants' perspectives and did not wish to impose a standardized categorization of the experiences, a standardized assessment tool for ADC could be useful. Experiences with similar phenomenology, such as NDEs, do have a standardized means for assessing whether a reported experience is an NDE and the depth — number and intensity of features—of that experience (e.g., the Near-Death Experience Scale; Greyson, 1983). Future research could be oriented toward development of a standard assessment measure of ADC for empirical purposes, and the typological nature of our study, as well as previous research such as Streit-Horn's (2011), could be useful for such development.

\section{Conclusion}

Losing a loved one through death is an emotionally stressful and traumatic experience for anyone, the impact of which may last a lifetime. Adherents to reductionist, materialist norms of reality and popular beliefs see death as a process of annihilation from which nothing remains. Death is believed to be the end of life and permanent and complete separation from loved ones. Yet the findings of the present study align with those of previous research, both on ADCs and on related phenomena, suggesting that for some people the connection with loved ones does not end with physical death. Communication with deceased others can occur, and when it does it is a largely welcome and beneficial experience. It brings comfort to the bereaved who come to feel they have not lost their loved ones for good. It also brings a sense of continuity: The bereaved not only feel that their relationships with the deceased have somehow persisted post-death but that they too may en- 
joy consciousness post-death. It also leads to existential benefit in the form of personal and spiritual growth, including a loss of fear of death. ADC has important implications not just for the bereaved but also for humanity as a whole. It challenges norms of reality. It challenges beliefs about death. However, the real challenge is whether humanity is willing and ready to engage with ADC accounts in a serious way and reap the seeds of their beneficial implications. A Copernican revolution may yet await us. As eminent Swiss psychologist and psychiatrist Carl Jung noted decades ago,

There are universal reports of these post-mortem phenomena ... They are based in the main on psychic facts which cannot be dismissed out of hand. Very often the fear of superstition, which strangely enough, is the concomitant of universal enlightenment, is responsible for the hasty suppression of extremely interesting reports which are then lost to science. (Jung, 1964, p. 316)

\section{References}

Alvarado, C. (2014). 'Visions of the dying', by James H Hyslop (1907): With an introduction by Carlos S. Alvarado. History of Psychiatry, 25, 237-252.

Arcangel, D. (2005). Afterlife encounters survey: The results. Journal of the American Society for Psychical Research, 91, 82-95.

Asai, M., Fujimori, M., Akizuki, N., Inagaki, M., Matsui, Y., \& Uchitomi, Y. (2010). Psychological states and coping strategies after bereavement among the spouses of cancer patients: a qualitative study. Psycho-Oncology, 19, 38-45.

Attig, T. (2004). Disenfranchised grief revisited: Discounting hope and love. OMEGA; Journal of Death and Dying, 49(3), 197-215.

Barbato, M., Blunden, C., Reid, K., Irwin, H., \& Rodriguez, P. (1999). Parapsychological phenomena near the time of death. Journal of Palliative Care, 15(2), 30-37.

Botkin, A. (2000). The induction of after-death communications utilizing eye movement desensitization and reprocessing: A new discovery. Journal of NearDeath Studies 18(3), 181-209.

Botkin, A. L., \& Hannah, M. T. (2013). Psychotherapeutic outcomes reported by therapists trained in induced after-death communication. Journal of NearDeath Studies, 31(4), 221-224.

Botkin, A. L., \& Hogan, R. C. (2005). Induced After Death Communication: A new therapy for healing grief and traumatic loss. Charlottesville, VA: Hampton Roads.

Braun, V., \& Clarke, V. (2006). Using thematic analysis in psychology. Qualitative Research in Psychology, 3, 77-101.

Breakwell, G. M. (1995). Interviewing. In G. M. Breakwell, S. Hammond, \& C. Fife-Shaw (Eds.), Research methods in psychology (pp. 230-242). London, England, UK: Sage.

Carpentier, N., \& Van Brussel, L. (2012). On the contingency of death: A 
discourse-theoretical perspective on the construction of death. Critical Discourse Studies, 9(2), 99-115.

Cooper, C. E. (2013). Post death experiences and the emotion of hope. Journal for Spiritual and Consciousness Studies, 36(1), 24-28.

Datson, S. L., \& Marwit, S. J. (1997). Personality constructs and perceived presence of deceased loved ones. Death Studies, 21(2), 131-146.

Devers, E. (1994). Experiencing the deceased (Unpublished doctoral dissertation). University of Florida, Gainesville, FL.

Devers, E. (1997). Goodbye again: Experiences with departed loved ones. Kansas City, MO: Andrews and McMeel.

Drewry, D. (2002). Purported after-death communication and its role in the recovery of bereaved individuals: A phenomenological study (Unpublished doctoral dissertation). California Institute for Human Science, Encinitas, CA.

Drewry, M. D. J. (2003). Purported after-death communication and its role in the recovery of bereaved individuals: A phenomenological study. Proceedings of the Annual Conference of the Academy of Religion and Psychical Research, 74-87.

Field, N. P., \& Friedrichs, M. (2004). Continuing bonds in coping with the death of a husband. Death Studies, 28, 597-620.

Flynn, C. P. (1986). After the beyond. Human transformation and the near-death experience. Englewood Cliffs, NJ: Prentice-Hall.

Gamino, L. A., Sewell, K. W., \& Easterling, L. W. (2000). Scott and White grief study-Phase 2: Toward an adaptive model of grief. Death Studies, 24, $633-660$.

Grey, M. (1985). Return from death: An exploration of the near-death experience. London, England, UK: Arkana.

Greyson, B. (1983). The Near-Death Experience Scale: Construction, reliability, and validity. Journal of Nervous and Mental Disease, 171, 369-375.

Greyson, B. (2003). Incidence and correlates of near-death experiences in a cardiac care unit. General Hospital Psychiatry, 25, 269-276.

Greyson, B. (2010). Seeing dead people not known to have died: "Peak in Darien" experiences. Anthropology and Humanism, 35(2), 159-171.

Greyson, B., \& Khanna, S. (2014). Spiritual transformation after near-death experiences. Spirituality in Clinical Practice, 1(1), 43-55.

Greyson, B., \& Stevenson, I. (1980). The phenomenology of near death experiences. American Journal of Psychiatry, 137, 1193-1196.

Guggenheim, B., \& Guggenheim, J. (1995). Hello from heaven! New York, NY: Bantam.

Halman, L. (2001). The European Values Study: A third wave. Sourcebook of the 1999-2000 European Values Study Surveys. Tilburg, The Netherlands: Tilburg University.

Hannah, M., Botkin, A., Marone, J., \& Streit-Horn, J. (2013). Induced after death communication: an update. Journal of Near-Death Studies, 31(4), 213-220.

Haraldsson, E. (1988). Survey of claimed encounters with the dead. Omega, Journal of Death and Dying, 19(2), 103-113.

Haraldsson, E. (2006). Popular psychology, belief in life after death and reincarnation in the Nordic countries, Western and Eastern Europe. Nordic Psychology, 58, 171-180.

Hastings, A., Hutton, M., Braud, W., Bennett, C., Berk, I., Boynton, T., ... 
Steinbach-Humphrey, S. (2002). Psychomanteum research: Experiences and effects on bereavement. Omega: Journal of Death and Dying, 43(3), 211-228.

Holmes T. H., \& Rahe, R. H. (1967). The Social Readjustment Rating Scale. Journal of Psychosomatic Research, 11(2), 213-8. doi:10.1016/0022-3999(67)90010-4

Jung, C. G. (1964). The psychological foundation of belief in spirits. Collected Works (Vol. 8). London, England, UK: Routledge and Kegan Paul.

Kalish, R. A., \& Reynolds, D. K. (1973). Phenomenological reality and post-death contact. Journal for the Scientific Study of Religion, 12(2), 209-221.

Kelly, R. E. (2002). Post mortem contact by fatal injury victims with emergency service workers at the scenes of their death. Journal of Near-Death Studies, 21(1), 25-33.

Khanna, S., \& Greyson, B. (2014). Near-death experiences and spiritual wellbeing. Journal of Religion and Health, 53(6), 1605-1615.

Klass, D. (1993). Solace and immortality: bereaved parents' continuing bonds with their children. Death Studies, 17, 343-368.

Klugman, C. M. (2006). Dead men talking: Evidence of post death contact and continued bonds. Omega: Journal of Death and Dying, 53(3), 249-226.

LaGrand, L. E. (1997). After-death communication: Final farewells. St. Paul, MN: Llewellyn.

LaGrand, L. E. (1999). Messages and miracles. St. Paul, MN: Llewellyn.

LaGrand, L. E. (2005). The nature and therapeutic implications of the extraordinary experiences of the bereaved. Journal of Near-Death Studies, 24, 3-20.

Lai, C. F., Kao, T. W., Wu, M. S., Chiang, S. S., Chang, C. H., Lu, C. S., . . . Chen, W. Y. (2007). Impact of near-death experiences on dialysis patients: A multicenter collaborative study. American Journal of Kidney Diseases, 50(1), $124-132$.

Lawrence M., \& Repede, E. (2013). The incidence of deathbed communications and their impact on the dying process. American Journal of Hospice and Palliative Care, 30(7), 632-639.

Long, J. P. (1999). After death communication overview. Retrieved from http:// www.adcrf.org/ADC\%200verview.htm.

MacDonald, W. L. (1992). Ideonecrophanies: The social construction of perceived contact with the dead. Journal for the Scientific Study of Religion, 31(2), 215-223.

Marris, P. (1958). Widows and their families. London, England, UK: Routledge and Kegan Paul.

Marris, P. (1974). Loss and change. New York, NY: Pantheon Books.

Nowatski, N., \& Kalischuk, R. (2009). Post-death encounters: Grieving, mourning, and healing. Omega: Journal of Death and Dying, 59(2), 91-111.

Noyes, R., Fenwick, P., Holden, J. M., \& Christian, R. (2009). Aftereffects of pleasurable Western adult near-death experiences. In J. M. Holden, B. Greyson, \& D. James (Eds.), The handbook of near-death experiences: Thirty years of investigation (pp. 41-62). Santa Barbara, CA: Praeger/ABC-CLIO.

Olson, P. R., Suddeth, J. A., Peterson, P. J., \& Egelhoff, C. (1985). Hallucinations of widowhood. Journal of the American Geriatrics Society, 33(8), 543-547.

Parker, J. S. (2005). Extraordinary experiences of the bereaved and adaptive outcomes of grief. Omega: Journal of Death and Dying, 51(4), 257-283.

Parkes, C. M. (1970). The first year of bereavement. Psychiatry, 33, 444-467. 
Rahe, R. H., \& Arthur, R. J. (1978). Life change and illness studies: Past history and future directions. Journal of Human Stress, 4(1), 3-15.

Rees, D. (1971). The hallucinations of widowhood. British Medical Journal, 4(5778), 37-41.

Ring, K. (1980). Life at death: A scientific investigation of the near-death experience. New York, NY: Coward, McCann and Geoghegan.

Ring, K. (1984). Heading toward omega: In search of the meaning of the neardeath experience. New York, NY: Coward, McCann \& Geohegan.

Sabom, M. B. (1982). Recollections of death: A medical investigation. New York, NY: Harper and Row.

Schwaninger, J., Eisenberg, P. R., Schectman, K. B., \& Weiss, A. N. (2002). A prospective analysis of near-death experiences in cardiac arrest patients. Journal of Near-Death Studies, 20, 215-232.

Shuchter, S. R., \& Zisook, S. (1988). Widowhood: The continuing relationship with the dead spouse. Bulletin of the Menninger Clinic, 52(3), 269-279.

Smith, P. C., Range, L. M., \& Ulmer, A. (1991-1992). Belief in the afterlife as a buffer in suicidal and other bereavements. Omega: Journal of Death and Dying, 24, 217-225.

Solomon, S., Greenberg, J., \& Pyszczynski, T. (1991). A terror management theory of social behaviour: The psychological functions of self-esteem and cultural worldviews. Advances in Experimental Social Psychology, 24, 93-159.

Steffen, E., \& Coyle, A. (2011). Sense of presence experiences and meaningmaking in bereavement: A qualitative analysis. Death Studies, 35(7), 79-609.

Streit-Horn, J. (2011). A systematic review of research on after-death communication $(A D C)$ (Unpublished doctoral dissertation). University of North Texas: Denton, TX.

Stroebe, M., Schut, H., \& Stroebe, W. (2005). Attachment in coping with bereavement: a theoretical integration. Review of General Psychology, 9, 48-66.

Sutherland, C. (1990). Changes in religious beliefs, attitudes, and practices following near-death experiences: An Australian study. Journal of Near-Death Studies, 9, 21-31.

Tassell-Matamua, N. A., \& Lindsay, N. (2015). "I'm not afraid to die": The loss of the fear of death after a near-death experience. Mortality, 21(1), 71-87. doi:10 $.1080 / 13576275.2015 .1043252$

Tassell-Matamua, N. A., \& Murray, M. (2014). Near-death experiences: Quantitative findings from an Aotearoa New Zealand sample. Journal of Near-Death Studies, 33(1), 2-29.

Tassell-Matamua, N. A., \& Steadman, K. (2015). Of love and light: A case report of end-of-life experiences. Journal of Near-Death Studies, 34(1), 5-26.

Tyson-Rawson, K. (1996). Relationship and heritage: Manifestations of ongoing attachment following father death. In D. Klass, P. R. Silverman, \& S. Nickman (Eds.), Continuing bonds: New understandings of grief (pp. 125-145). Philadelphia, PA: Taylor \& Francis.

van Lommel, P. (2004). About the continuity of our consciousness. Advances in Experimental Medicine and Biology, 550, 115-132.

van Lommel, P., van Wees, R., Meyers, V., \& Elferrich, I. (2001). Near death experiences in survivors of cardiac arrest. A prospective study in the Netherlands. The Lancet, 358, 2039-2045. 
Vickio, C. J. (1999). Together in spirit: Keeping our relationships alive when loved ones die. Death Studies, 23(2), 161-175.

Wiener, L., Aikin, A., Gibbons, M. B., \& Hirschfeld, S. (1996). Visions of those who left too soon. American Journal of Nursing, 96(9), 57-61.

Worden, J. W. (2002). Grief counseling and grief therapy: A handbook for the mental health practitioner. New York, NY: Springer.

Yamamoto, J., Okonogi, K., Iwasaki, T., \& Yoshimura, S. (1969). Mourning in Japan. American Journal of Psychiatry, 125(12), 1660-1665.

Zingrone, N. L., \& Alvarado, C. S. (2009). Pleasurable Western adult near-death experiences: Features, circumstances, and incidence. In J. M. Holden, B. Greyson, \& D. James (Eds.), The handbook of near-death experiences: Thirty years of investigation (pp. 17-40). Santa Barbara, CA: Praeger/ABC-CLIO. 